\title{
Influence of personality psychology on outcome of total hip arthroplasty: a cross-sectional study on 69 patients
}

\author{
Trevisan Carlo Lauro (1), Klumpp Raymond (1), Compagnoni Riccardo (1)
}

1 - ASST Bergamo Est, Ospedale Bolognini, Via Paderno, 48. Seriate (BG)

\section{Introduction}

Clinicians have traditionally focused on radiographic measurements and functional performance to rate success after total hip arthroplasty. In the last years, patient satisfaction rating has become an important marker of surgical success. In this regards, factors other than biomechanical consideration and physical function characteristics may influence patient postoperative outcome (1) Patient Reported Outcome Measures are increasingly used to assess the results of joint arthroplasty (2). They directly measure the patient's evaluation of their treatment and indirectly measure the ability of the health care process to meet patient expectation and in some countries they are used as a discriminating factor in health care commissioning and funding for hospitals (3).

Therefore, identifying predictive factors for satisfaction may allow intervention to further increase patient satisfaction. Since 1950's many studies have been conducted to find a correlation between patient's psychology and aim of results in many surgical procedures. One of the most famous scale is the Health locus of control, an important component in social learning theory models designed to predict behaviours and cognitive processes relevant to mental and physical health. (4) This was first described by Wallston in 1976, then corrected in Multidimensional Health locus of control in 1978. $(5,6)$. The MHLC usually include three dimensions: Internal, powerful others and chance. Many studies over the last several years demonstrated that an internal sense of personal control is related in positive ways to physical adaptation to illness as well as engagement in beneficial health behaviours (7). An external health locus of control refers to the belief that one's outcome after injury or surgery is under the control of powerful others or is determined by fate, luck, or chance. An internal health locus of control refers to the belief that one's outcome is directly related to individual patient behaviours. Health locus of control has been shown to influence the recovery process after injury and anterior cruciate ligament reconstruction. (8) Two potential influencing factors have been disregarded in patient satisfaction studies: the experience of pain during recovery and patient's health locus of control.

The aim of our study was to examine the incidence of patient satisfaction after THA surgery, to describe the relationship between patient-derived functional scores and other potential influencing 
factors and satisfaction, and to investigate the relationship between satisfaction and the health locus of control.

Methods

We conducted a cross-sectional study on a cohort of consecutive series of patients, operated of total hip arthroplasty in our Department from November 2008 to August 2011, screened for a comparative survey between mini-invasive direct anterior and direct lateral hip approach for total hip replacement. Inclusion criteria of the survey were: body mass index (BMI)<40, diagnosis of primary hip arthritis (OA) or avascular necrosis of the hip (ANH), age $<80$ years and modified Charnley co-morbidity classification equal to A or B2 (17).

One hundred fourteen patients were screened, 79 met the inclusion criteria and $69(87,3 \%)$ were revised and completed the study

All the patients gave informed consent prior to being included in the study. The study was performed in accordance with the ethical standards of the 1964 Declaration of Helsinki as revised in 2000.

Surgical procedures were performed by the same surgeon (CT) either under general or under spinal anaesthesia.

All patients received the same standardised post-operative care. Pharmacological antithrombotic prophylaxis was used and intravenous antibiotics were administered for $24 \mathrm{~h}$ after surgery. The suction drain was removed on the first postoperative day and patients were switched to oral narcotics on the $2^{\text {nd }}$ or $3^{\text {rd }}$ postoperative day. Physical therapy began the day after surgery, weightbearing was allowed on the first postoperative day.

Demographic information and the postoperative course including post-operative complications were determined from a review of office charts. Pre- and postoperative hip function was assessed by the Harris Hip Score (HHS) (9).

At the follow-up visit, patient satisfaction was assessed by means of the Patient Satisfaction Questionnaire (marshall completo o ridotto!).

The memory of pain experienced by the patient during hospital stay was evaluated by a modified questionnaire on pain experience (!!) (see appendix): the first item "how clearly do you remember the pain you experienced while you were in hospital being operated of total hip arthroplasty was rated on a 1 (not at all) to 5 (very much) scale, then patients were invited to rate the level of pain they experienced while resting, during dressing changes, and physical activity while in the in- 
patient setting on 10 -point scales ( $0=$ no pain; $10=$ pain as bad as you can imagine). Satisfaction was evaluate with the Patient Satisfaction Questionnaire (!!).

Postoperative radio-graphs were evaluated for components position. The parameters recorded were stem alignment and cup inclination angle. Stem alignment was measured as the angle between the long axis of the femoral stem and the anatomical axis of the femur on the anterior-posterior radiography. Multidimensional Health locus of control was evaluated in all patients before the surgery and results were connected with Harris Hip Score, patient's subjective satisfaction and pain indexes to evaluate how a different mhlc can modify results in total hip arthroplasty. Citare il questionario di soddisfazione del paziente.

\section{Results}

We included in our study 69 patients with an average BMI of $26(18,4-36,3), 37$ male and 32 female with a pre-operative Harris Hip Score of 49,3 (20-74) while mean post-operative Harris Hip Score was 94,4 (40-100). The IHLC was 25,3 (0-36), CHLC was 18,9 (0-36) and EHLC was 23,5 (0-36) (Valori medi o appartenenza a gruppi?)(table 1). Patient satisfaction after THA ranged from $61 \%$ of the patients being very satisfied, 33\% satisfied, $4 \%$ unsatisfied and $1 \%$ very unsatisfied (figure 1). Global patient satisfaction was compared to the data obtained from the functional scores in order to see if there was any correlation between the two using an ordered logistic regression model (table 2). In fact better global patient satisfaction seemed to be correlated with a higher IHLC, with a higher pre-operative HHS and with a higher HHS delta, though none of them were statistically significant (???). This may be due to the fact that the subgroups in the global patient satisfaction cohort are too many and that there is the need to rationalize patient satisfaction in just 2 groups (satisfied and less satisfied) in order to show significance of correlation between MHLC and patient outcome after THA. We therefore evaluated the patients through a questionnaire (table 3 ) consisting of 5 simple questions (with scores ranging from 1 (very unsatisfied) to 4 (very satisfied) for each question). All patients obtaining an overall score of at least 15 out of 20 were part of the satisfied group (38\%), whereas patients obtaining less than 15 point were part of the less satisfied group (62\%) (figure 2). The statistical analysis ( two-sample Kolmogorov-Smirnov test) of IHLC, CHLC and EHLC among the two patient satisfaction groups (satisfied and less-satisfied) showed that patients with a higher IHLC were more likely to be of the satisfied patient group (table 4). This was statistically significant $(p<0,05)$.

\section{Discussion}


Nowadays patients satisfaction has become the main goal after a surgical procedure, and many questionnaires and clinical tests have been developed to create an objective evaluation of clinical and physical results. Patient satisfaction is connected with many aspects of clinical practice as of compliance, better surgical results, a reduction of legal controversies and general rating of medical care.(11). In orthopaedic surgery many studies also have evidenced that patient satisfaction is complex and does not necessarily have a clear link to either existing patient-reported outcomes or outcomes measured by clinicians (11). First it is important to discriminate between satisfaction related to the outcome of care or with the process of care. Many studies have analysed this feature beginning from the $80^{\prime}$ and a list of scores or quality evaluation have been formulated from the American Academy of Orthopaedic Surgeons, National Research Corporation Picker, Centres for Medicare \& Medicaid Services, Consumer Assessment of Healthcare Providers and Systems and many more institutions (12). In contrast only few studies and analysis are reported in physiotherapy and rehabilitation literature that describe the connection between patient's psychological characteristics and results of rehabilitation after a trauma or a surgical procedure. In these years some authors have developed studies to analyze the patient's psychological attitude to results of medical treatments. One of the commonly used is the Multidimensional Health Locus of Control, described for the first time by Wallston in 1978 (6). The MHLC usually includes three dimensions: Internal, powerful others and chance. Many studies over the last several years demonstrated that an internal sense of personal control is related positively to physical adaptation to illness as well as engagement in beneficial health behaviour. The aim of our study was to examine the incidence of patient satisfaction after THA surgery, to describe the relationship between patient-derived functional scores and other potential influencing factors and satisfaction, and to investigate the relationship between satisfaction and the health locus of control. We used scores routinely used in clinical practice as the Harris Hip score and tried to make a connection of these results with patients' preoperative multidimensional health locus of control. Connecting the data we proved, with a statistically significant evidence, that patients included in the ILHC obtained better results both in clinical results tested with HHS as in subjective satisfaction evaluated with the Patient Satisfaction Questionnaire.

These data confirm what is evidenced in two different studies on Anterior Cruciate Ligament Reconstruction in which perceived sports involvement was related to involved lower extremity neuromuscular adaptations, better subjective knee function, a more internal HLOC and higher sports activity intensity levels. $(13,14)$ 
Correlation between rehabilitation results and Multidimensional Health locus of control is described in many other studies about rehabilitation in low back pain, fibromyalgia syndrome and rheumatoid arthritis. $(15,16)$

To achieve a good results in orthopaedic surgery and rehabilitation many parameters have been used in the last decades, with a definitely larger comprehension of patient's wishes and needs. A real satisfaction is possible only if the patient will be able to participate to his desired activities of daily living. Results of our study can be useful, in correlation with other parameters as age and associated disease, to identify the group of patients undergoing surgery with a higher risk of bad results and take actions to improve outcomes. Possible actions should focus on patient's motivation and incitement to take care of his own health and implement his actions to reach the final target that is the complete healing.

Multidimensional Health locus of control can be considered a predictor of patient's satisfaction after an invasive surgical procedure as total hip arthroplasty. More studies should be performed to develop strategies for making the health care process more successful in that part of patients that seem to be more dependent on external control of their health.

1 - Greenhalgha J, Longa AF, Flynnb R The use of patient reported outcome measures in routine clinical practice: lack of impact or lack of theory? Social Science \& Medicine 60 (2005) 833-843

2 - Franklin PD, Lewallen D, Bozic K, Hallstrom B, Jiranek W, Avers DC. Implementation of patient-reported outcome measures in U.S. Total joint replacement registries: rationale, status, and plans. J Bone Joint Surg Am 2014 Dec 17;96 Suppl 1:104-9. doi: 10.2106/JBJS.N.00328.

3 - Black N, Patient reported outcome measures could help transform healthcare. BMJ 2013 Jan 28;346:f167. doi: 10.1136/bmj.f167.

4 - Masters K.S., Wallston KA, Canonic correlation reveals important relations between health locus of control, coping, affect and values, Journal of health psychology vol 10(5) 719-731 2005

5 - Wallston B.S., Wallston K.A., Kaplan G.D., Maides S.A., (1976)The development and validation of the health related locus of control (HLC) scale. Journal of Consulting and Clinical Psychology, 44, 580-585.

6 - Wallston K.A., Wallston B.S., DeVellis R., (1978) Multidimensional Health Locus of Control (MHLC) Scales, Health Education Monographs, 6, 160-170.

7 - Affleck G, Tennen H, Pfeiffer C, Fifield J, Rowe J, Downward comparison and coping with serious medical problems, Am J Orthopsychiatry 1987 Oct;57(4):570-8.

8 - Nyland J, Cottrell B, Harreld K, Caborn DNM, Self-Reported Outcomes After Anterior Cruciate Ligament Reconstruction: An Internal Health Locus of Control Score Comparison Arthroscopy: The Journal of Arthroscopic and Related Surgery, Vol 22, No 11 (November), 2006: pp 1225-1232 
9 - Harris WH. Traumatic arthritis of the hip after dislocation and acetabular fractures: treatment by mold arthroplasty. An end-result study using a new method of result evaluation. J Bone Joint Surg Am. 1969 Jun;51(4):737-55.

10 - Michiel G. J. S. Hageman MGJS, Brie“t JP, Bossen JK, Blok R, Ring DC, Vranceanu A-M Do Previsit Expectations Correlate With Satisfaction of New Patients Presenting for Evaluation With an Orthopaedic Surgical Practice? Clin Orthop Relat Res (2015) 473:716-721

11 - . Hickson GB, Clayton EW, Entman SS, Miller CS, Githens PB, Whetten-Goldstein K, Sloan FA. Obstetricians' prior malpractice experience and patients' satisfaction with care. JAMA. 1994;272:1583-1587. doi:10.1001/jama.287.22.2951

12 - Graham B, Green A, James M, Katz J, Swiontkowski M, Measuring Patient Satisfaction in Orthopaedic Surgery J Bone Joint Surg Am. 2015(97)80-4 doi 10.2106/JBJS.N.00811

13 - Nyland J, Mauser N, Caborn DM Sports involvement following ACL reconstruction is related to lower extremity neuromuscular adaptations, subjective knee function and health locus of control. Knee Surg Sports Traumatol Arthrosc (2013) 21:2019-2028 DoI 10.1007/s00167-013-2366-6

14 - Nyland J, Cottrell B, Harreld K, Caborn DNM, Self-Reported Outcomes After Anterior Cruciate Ligament Reconstruction: An Internal Health Locus of Control Score Comparison Arthroscopy: The Journal of Arthroscopic and Related Surgery, Vol 22, No 11 (November), 2006: pp 1225-1232

15 - Keedy NH, Keffala VJ, Altmaier EM, Chen JJ Health locus of control and self-efficacy predict back pain rehabilitation outcomes. Iowa Orthop J 2014;34:158-65

16 - Gustafsson M, Gaston-Johansson F, Pain intensity and health locus of control: a comparison of patients with fibromyalgia syndrome and rheumatoid arthritis. Patient educ Couns 1996 Nov;29(2):179-88.

17. Charnley J. The long-term results of low-friction arthroplasty of the hip performed as a primary intervention. J Bone Joint Surg (Br) 1972; 54 (1): 61-76. 


\begin{tabular}{|c|c|c|}
\hline \multicolumn{2}{|l|}{ Sex (male/female) } & $37 / 32$ \\
\hline \multicolumn{2}{|l|}{ ASA $1 / 2 / 3$} & $16 / 33 / 20$ \\
\hline \multicolumn{2}{|c|}{ Charnley comorbidity score A / B2 } & $64 / 5$ \\
\hline Age (years) & $\begin{array}{l}\text { mean } \pm S D \\
\text { range }\end{array}$ & $\begin{array}{c}63 \pm 9.5 \\
30-80\end{array}$ \\
\hline Body Mass Index & $\begin{array}{l}\text { mean } \pm S D \\
\text { range }\end{array}$ & $\begin{array}{c}26 \pm 3.5 \\
18.4-36.3\end{array}$ \\
\hline Preoperative Harris Hip Score & $\begin{array}{l}\text { mean } \pm S D \\
\text { range }\end{array}$ & $\begin{array}{c}49.3 \pm 12.8 \\
20-74\end{array}$ \\
\hline Postoperative Harris Hip Score & $\begin{array}{l}\text { mean } \pm S D \\
\text { range }\end{array}$ & $\begin{array}{c}94.4 \pm 9.7 \\
40-100\end{array}$ \\
\hline Internal Health Locus Control & $\begin{array}{l}\text { mean } \pm S D \\
\text { range }\end{array}$ & $\begin{array}{c}25.3 \pm 5.5 \\
0-36\end{array}$ \\
\hline Chance Health Locus Control & $\begin{array}{l}\text { mean } \pm S D \\
\text { range }\end{array}$ & $\begin{array}{c}18.9 \pm 6.6 \\
0-36\end{array}$ \\
\hline External Health Locus Control & $\begin{array}{l}\text { mean } \pm S D \\
\text { range }\end{array}$ & $\begin{array}{c}23.5 \pm 7.1 \\
0-36\end{array}$ \\
\hline
\end{tabular}

Table 1 Demographic and clinical data 


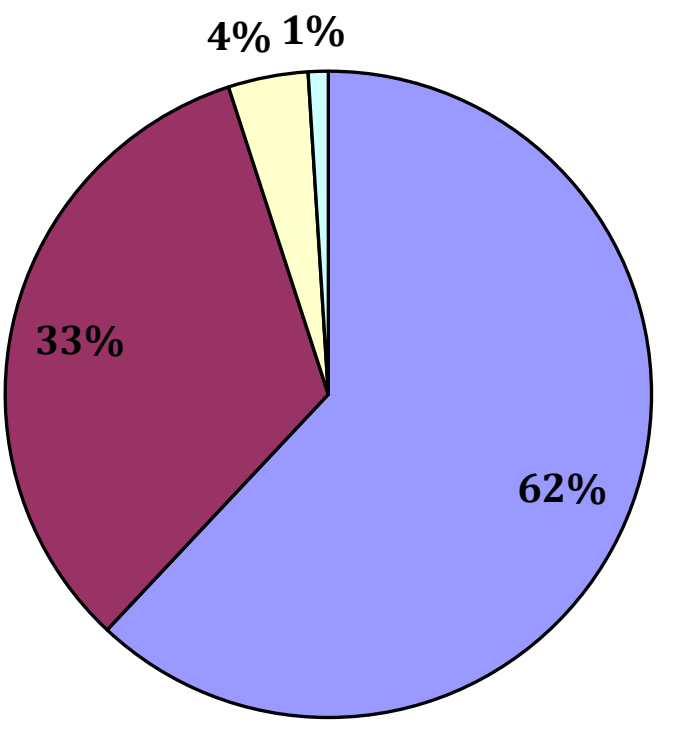

$\square$ very satified

$\square$ satisfied

$\square$ unsatisfied

$\square$ very unsatisfied

Figure 1 Global Patient Satisfaction after Total Hip Arthroplasty 
Table 2 Correlation between Global Patient Satisfaction Questionnarie and patient-related functional scores (Ordered Logistic Regression) 
Division in 2 distinctive patient satisfaction groups through a score obtained of 5 questions.

Admission in "satisfied patient group" requires a score of at least 15 / 20 points. All patients with a score of less than 15 points are part of the "less satisfied patient group".

Question 1:

How would you judge the satisfaction of your Total Hip Arthroplasty?

\begin{tabular}{|c|c|c|c|c|}
\hline Judgement & Very satisfied & Satisfied & Unsatisfied & Very unsatisfied \\
\hline Score & 4 & 3 & 2 & 1 \\
\hline
\end{tabular}

Question 2:

How would you judge the reduction of pain obtained after surgery?

\begin{tabular}{|c|c|c|c|c|}
\hline Judgement & Very satisfied & Satisfied & Unsatisfied & Very unsatisfied \\
\hline Score & 4 & 3 & 2 & 1 \\
\hline
\end{tabular}

Question 3:

How would you judge the success of your surgical intervention in terms of raise of activity of daily living?

\begin{tabular}{|c|c|c|c|c|}
\hline Judgement & Very satisfied & Satisfied & Unsatisfied & Very unsatisfied \\
\hline Score & 4 & 3 & 2 & 1 \\
\hline
\end{tabular}

Question 4:

How would you judge the success of you surgical intervention in terms of lifting weights? 


\begin{tabular}{|c|c|c|c|c|}
\hline Judgement & Very satisfied & Satisfied & Unsatisfied & Very unsatisfied \\
\hline Score & 4 & 3 & 2 & 1 \\
\hline
\end{tabular}

Question 5:

How would you judge your surgical intervention related to your expectations before you underwent surgery?

\begin{tabular}{|c|c|c|c|c|}
\hline Judgement & Very satisfied & Satisfied & Unsatisfied & Very unsatisfied \\
\hline Score & 4 & 3 & 2 & 1 \\
\hline
\end{tabular}

Table 3 Modified “5 Question” Patient Questionnaire
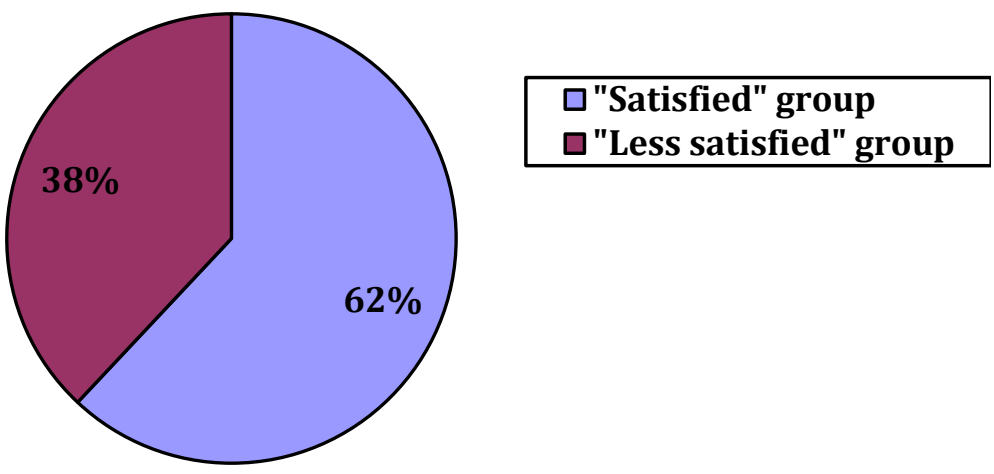

Figure 2 Modified "5 Question" Patient Satisfaction Questionnaire after Total Hip Arthroplasty 


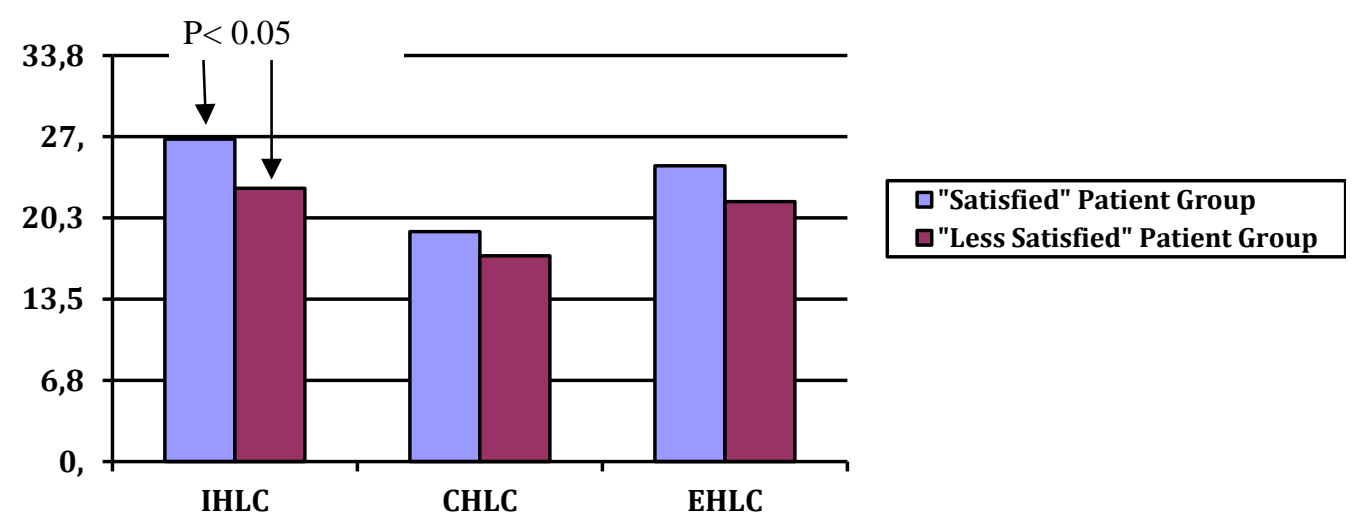

Figure 3 Correlation between Mean Health Locus Control Groups and Modified "5 Question" Patient Satisfaction Questionnaire Groups (two-sample Kolmogorov-Smirnov test for equality of distribution functions) showed statistical significance between higher IHLC and Patient Satisfaction ( $<<0,05)$. 
